\title{
THE EFFECTIVENESS OF BEDSIDE TEACHING LEARNING METHODS TOWARDS THE SELF-EFFIFACY OF THERAPEUTIC COMMUNICATION IN MIDWIFERY STUDENTS IN CLINICAL PRACTICE
}

\author{
Dwi Rahmawati ${ }^{1 *}$, Ova Emilia ${ }^{2}$, Yekti Satriandari ${ }^{3}$, Yoyo Suhoyo ${ }^{1}$ \\ ${ }^{1}$ Mahasiswa Prodi IImu Kebidanan Program Magister Kebidanan Universitas 'Aisyiyah, Yogyakarta - INDONESIA \\ ${ }^{2}$ Fakultas Kedokteran, Kesehatan Masyarakat dan Keperawatan, Universitas Gadjah Mada, Yogyakarta - INDONESIA \\ ${ }^{3}$ Prodi Kebidanan Program Diploma IV Kebidanan Universitas Aisyiyah, Yogyakarta - INDONESIA
}

Submitted: 05 July 2019 ; Final Revision from Author: 17 July 2020; Accepted: 20 July 2020

\begin{abstract}
Background: One of the competencies that must be mastered by health workers is therapeutic communication. Effective communication can increase patient satisfaction but on the contrary communication failure can cause poor information exchange, misdiagnosis, decreased participation and stressors in patients, and even death. Poor communication can be caused by low self efficacy. Bedside teaching learning through preseptor modeling can affect self efficacy in communication. The study aimed to determine the effectiveness of bedside teaching learning method towards the self-efficacy of therapeutic communication in midwifery students in clinical practice.

Method: This research is a quantitative descriptive study. The research sample was all midwifery students in the fifth semester who had clinical practice at PKU Muhammadiyah Hospital of Gamping, and Queen Latifa Hospital as many as 20 students. The sampling technique used saturated features. The research instrument used SE-12 and the preceptor's assessment in bedside teaching. The bivariate analysis used paired t-test and independent $t$-test.

Results: The results showed that the self-efficacy analysis of prior and after bedside teaching therapentic communication in the certified group obtained mean different of 19.50 and those in the non-certified group obtained mean different of 5.13. There were differences, but not statistically significant with p-value of 0.153 .

Conclusion: Bedside teaching effectively increased the self-efficacy of midwifery student communication taught by certified preceptors compared to non-certified preceptors. The stages of bedside teaching in the certified group had a better level of preceptor competence than the group that had not been certified. Clinical advisors are suggested to follow preceptors certification to increase knowledge.
\end{abstract}

Keywords: bedside teaching, communication self-efficacy.

\section{ABSTRAK}

Latar belakang: Salah satu kompetensi yang harus dikuasai tenaga kesehatan adalah komunikasi terapeutik. Komunikasi yang efektif dapat meningkatkan kepuasan pasien tetapi sebaliknya kegagalan komunikasi dapat menyebabkan pertukaran informasi yang buruk, kesalahan diagnosis, penurunan partisipasi dan menyebabkan stres pada pasien hingga kematian. Komunikasi yang buruk tersebut bisa disebabkan karena self efficacy rendah. Pembelajaran bedside teaching melalui pemodelan preseptor dapat mempengaruhi self efficacy

$\overline{\text { *corresponding author, contact: dwi_rahmawati8949@yahoo.com }}$ 
dalam komunikasi. Tujuan penelitian ini untuk mengetahui efektivitas metode pembelajaran bedside teaching tehadap self efficacy komunikasi terapeutik mahasiswa kebidanan dalam praktik klinik.

Metode: Penelitian ini merupakan penelitian deskriptif kuantitatif. Sampel penelitian seluruh mahasiswa kebidanan semester lima yang sedang praktik klinik di RS PKU Muhammadiyah gamping dan RS Queen latifa sebanyak 20 mahasiswa. Teknik pengambilan sampel menggunakan sampling jenuh. Instrumen penelitian menggunakan SE-12 dan penilaian preseptor dalam bedside teaching. Analisis bivariat menggunakan paired t-test dan independent t-test.

Hasil: Hasil analisis self efficacy komunikasi terapeutik sebelum dan sesudah bedside teaching pada kelompok bersertifikat dengan mean different 19,50 dan pada pada kelompok belum bersertifikat dengan mean different 5,13. Terdapat perbedaan, namun secara statistik tidak signifikan dengan nilai p-value 0,153.

Kesimpulan: Bedside teaching efektif meningkatkan self efficacy komunikasi mahasiswa kebidanan yang diajarkan preseptor bersertifikat dibandingkan dengan preseptor belum bersertifikat. Tahap-tahapan bedside teaching pada kelompok bersertifikat memiliki tingkat kompetensi preseptor lebih baik dibandingkan kelompok belum bersertifikat. Saran diharapkan pembimbing klinik mengikuti pelatihan preseptor untuk meningkatkan pengetahuan.

Kata kunci: bedside teaching, self-efficacy komunikasi

\section{PRACTICE POINTS}

- Mahasiswa kebidanan yang diajarkan bedside teaching oleh preseptor bersertifikat memiliki self efficacy komunikasi lebih tinggi, program pengembangan kemampuan pembimbing klinik secara terstruktur seperti pelatihan preseptor mentor perlu diselenggarakan.

- Kompetensi preseptor pada tahapan-tahapan bedside teaching perlu dinilai pada setiap pelaksanaan bedside teaching.

\section{PENDAHULUAN}

Kegagalan komunikasi menyebabkan stres, kesalahan diagnosis, penurunan partisipasi pasien dalam rencana perawatan dan menghasilkan pertukaran informasi buruk bahkan kematian. ${ }^{1}$ Hasil analisis 2.455 peristiwa yang dilaporkan ke komisi mengungkapkan $70 \%$ disebabkan oleh kegagalan komunikasi dan $75 \%$ dari pasien ini meninggal. ${ }^{2}$ Kegagalan komunikasi pada ibu selama persalinan, kurangnya perhatian, sehingga memicu timbulnya gangguan stres pasca bersalin dan berdampak pada minat ibu untuk tidak kembali ke fasilitas kesehatan, secara global $64 \%$ wanita hamil tidak menerima ANC empat kali selama kehamilannya. ${ }^{3}$

Di Indonesia kurangnya minat ibu hamil ke fasilitas kesehatan dapat dilihat dari selisih cakupan K1 ideal dan $\mathrm{K} 4$, terdapat $11,9 \%$ dari ibu yang menerima K1 ideal tidak melanjutkan ANC sesuai standar minimal K4. ${ }^{4}$ Masalah tersebut dapat menyumbangkan angka kematian pada ibu. Saat ini AKI masih tinggi yaitu 216/100.000 kelahiran hidup. ${ }^{5}$ Sistem pendidikan Nasional pasal 1 dicantumkan bahwa pendidikan adalah usaha terencana untuk mewujudkan suasana belajar dan proses pembelajaran agar peserta didik secara aktif mengembangkan potensi dirinya untuk memiliki kekuatan spiritual keagamaan, pengendalian diri, kepribadian, kecerdasan, akhlak mulia, dan keterampilan yang diperlukan dirinya, masyarakat, bangsa dan negara. ${ }^{6}$

Peningkatan profesionalisme bidan harus disiapkan sejak masa pendidikan agar calon bidan dapat mengembangkan potensi dirinya melalui pembelajaran yang diakui oleh masyarakat. ${ }^{7}$ Metode pembelajaran bedside teaching memberi kesempatan peserta didik mengikuti proses pendidikan lebih realistis serta dapat mengembangkan empati peserta didik terhadap klien, memberikan feedback bagi peserta didik tentang pengambilan riwayat, pemeriksaan fisik, keterampilan presentasi 
kasus, komunikasi yang berpusat pada pasien, pengambilan keputusan klinis, kepemimpinan, dan profesionalisme. ${ }^{8}$ Role model preseptor juga memberikan dampak signifikan pada peningkatkan kompetensi, membentuk mahasiswa berkualitas seperti kejujuran, ketenangan, menghargai, kemampuan komunikasi yang baik dan peningkatan kepercayaan diri. ${ }^{9}$

Studi pendahuluan dilakukan penulis dengan mewawancarai pembimbing klinik Rumah Sakit yang mengatur pelaksaan praktik klinik mahasiswa di RS PKU Muhammadiyah Gamping dan RS Queen Latifa pada 2 November 2018. Hasil wawancara didapatkan bahwa total mahasiswa kebidanan semester $\mathrm{V}$ yang akan praktik klinik di dua Rumah Sakit tersebut pada Februari sampai April 2019 berjumlah 20 mahasiswa, di RS Queen Latifa metode pembelajaran bedside teaching sudah dilaksanakan tetapi pembimbing klinik belum diikutsertakan untuk pelatihan preseptor, sedangkan di RS PKU Muhammadiyah Gamping beberapa pembimbing klinik sudah mengikuti pelatihan preceptor dan pelaksanaan bedside teaching sudah berjalan, sehingga mahasiswa merasakan adanya manfaat bedside teaching diantaranya timbul self efficacy komunikasi. Penelitian ini dilakukan untuk mengetahui apakah metode pembelajaran bedside teaching efektif untuk pembelajaran self efficacy komunikasi terapeutik mahasiswa kebidanan.

\section{METODE}

Jenis penelitian ini merupakan jenis penelitian deskriptif kuantitatif, karena dalam penelitian ini mendeskripsikan keadaan yang terjadi pada saat sekarang secara sistematis dan faktual dengan tujuan untuk memaparkan serta penyelesaian dari masalah yang diteliti. Penelitian Deskriptif adalah penelitian yang dimaksudkan untuk menyelidiki keadaan, kondisi atau hal-hal lain yang sudah disebutkan, yang hasilnya dipaparkan dalam bentuk laporan penelitian. ${ }^{11}$ Peneliti tidak mengubah, menambah, atau mengadakan manipulasi terhadap objek atau wilayah penelitian. Peneliti hanya memotret apa yang terjadi pada diri objek atau wilayah yang diteliti, kemudian memaparkan apa yang terjadi dalam bentuk laporan penelitian secara lugas, seperti apa adanya.

Sampel penelitian menggunakan teknik nonprobability sampling dengan teknik sampling jenuh. Kriteria sampel yang memenuhi syarat untuk berpartisipasi adalah Mahasiswa program studi D-III kebidanan semester $\mathrm{V}$, mahasiswa yang bersedia ikut dalam penelitian, mahasiswa yang berusia 20 22 tahun. Sampel dikeluarkan dari penelitian jika mahasiswa yang tidak mengikuti proses penelitian sampai akhir.

Pengumpulan data menggunakan kuesioner SE-12 untuk mengukur self efficacy komunikasi terapeutik mahasiswa dan kuesioner penilaian preseptor dalam bedside teaching. Setelah mendapatkan surat kelaikan etik dari Universitas Aisyiyah Yogyakarta pada tanggal 08 Januari 2019, peneliti mengumpulkan responden untuk pengisian kuesioner self efficacy pada awal periode praktik klinik atau sebelum bedside teaching (pretest) dan sesudah bedside teaching (posttest), harapan peneliti dapat mengetahui self efficacy kompetensi komunikasi terapeutik mahasiswa sebelum dan sesudah bedside teaching. Selanjutnya bedside teaching diberikan pada kedua kelompok setiap 2 kali perminggu, keterampilan asuhan kebidanan melalui langkah pre-round, round dan post-round selama 30 menit, satu mahasiswa mendapatkan bedisde teaching sebanyak 8 kali yang dibimbing preseptor selama satu bulan dimulai pada Februari - April 2018.

Analisis data pada penelitian ini menggunakan uji paired t-test untuk membandingkan rata-rata dua set data (sebelum dan sesudah) yang saling berpasangan dan Independent t-test untuk membandingkan proporsi grup yang tidak saling berpasangan dan untuk dua subjek sampel berbeda.

\section{HASIL DAN PEMBAHASAN}

Tabel 1 dan 2 di bawah ini menampilkan hasil distribusi data bahwa variabel self efficacy pada kelompok bersertifikat dan tidak bersertifikat serta variabel preseptor menunjukkan terdistribusi normal dengan nilai p-value $>0,05$. 
Tabel 1. Distribusi frekuensi karakteristik dan homogenitas responden

\begin{tabular}{|c|c|c|c|c|c|c|}
\hline Karakteristik & & $\begin{array}{l}\text { mpok } \\
\text { vensi } \\
=12)\end{array}$ & \multicolumn{2}{|c|}{$\begin{array}{c}\text { Kelompok } \\
\text { kontrol } \\
(\mathrm{n}=8)\end{array}$} & Total & $p$ value \\
\hline Umur Mahasiswa & & & & & & 0.637 \\
\hline 20 Tahun & 6 & $30 \%$ & 4 & $20 \%$ & 10 & \\
\hline 21 Tahun & 5 & $25 \%$ & 4 & $20 \%$ & 9 & \\
\hline 22 Tahun & 1 & $5 \%$ & & & 1 & \\
\hline
\end{tabular}

Tabel 2. Uji normalitas data self efficacy komunikasi terapeutik dan preseptor antara kelompok bersetifikat dan kelompok belum bersetifikat

\begin{tabular}{lcc} 
Variabel & $\mathrm{n}$ & Sig.(p-value) \\
Self efficacy & & \\
$\quad$ Kelompok bersetifikat & 12 & 0,879 \\
$\quad$ Kelompok tidak bersetifikat & 8 & 0,435 \\
Preseptor & & \\
Perencanaan & 20 & 0,424 \\
Briefing & 20 & 0,512 \\
Perkenalan & 20 & 0,373 \\
Pelaksanaan & 20 & 0,649 \\
Debriefing & 20 & 0,709 \\
Feedback & 20 & 0,794 \\
\hline
\end{tabular}

Tabel 3 menunjukkan kelompok bersertifikat terdapat peningkatan rata-rata self efficacy sebelum dan sesudah bedside teaching yaitu 1,15 sedangkan pada 0,3.

Tabel 3. Hasil uji paired t-test self efficacy komunikasi sebelum dan sesudah pada kelompok bersertifikat dan kelompok belum bersertifikat

\begin{tabular}{|c|c|c|c|c|}
\hline \multirow[b]{2}{*}{ Variabel } & \multicolumn{2}{|c|}{ Self efficacy komunikasi } & \multirow[b]{2}{*}{ Mean different } & \multirow{2}{*}{$\begin{array}{l}\text { Sig. } \\
(p \text { value }))\end{array}$} \\
\hline & $\begin{array}{l}\text { Pretest } \\
\text { Mean }\end{array}$ & $\begin{array}{l}\text { Posttest } \\
\text { Mean }\end{array}$ & & \\
\hline Bedside Teaching kelompok bersertifikat & $\begin{array}{l}115,75 \\
(6,80) \\
\end{array}$ & $\begin{array}{r}135,25 \\
(7,95) \\
\end{array}$ & 19,50 & 0,013 \\
\hline $\begin{array}{l}\text { Bedside Teaching kelompok belum } \\
\text { bersertifikat }\end{array}$ & $\begin{array}{l}118,00 \\
(6,94)\end{array}$ & $\begin{array}{l}123,13 \\
(7,24)\end{array}$ & 5,13 & 0,443 \\
\hline
\end{tabular}

Tabel 4 menunjukkan perbedaan selisih hasil self efficacy antara kelompok bersertifikat dan kelompok belum bersertifikat menunjukkan terdapat perubahan dengan nilai mean different sebesar 0,85, dapat disimpulkan ada perbedaan yang signifikan secara kelompok belum bersertifikat peningkatan rata-rata self efficacy sebelum dan sesudah bedside teaching yaitu praktis. Namun, secara statistik tidak ada perbedaan self efficacy komunikasi antara kelompok bersertifikat dengan kelompok belum bersertifikat dengan nilai p-value 0,153 . 
Tabel 4. Perbedaan hasil self efficacy komunikasi pada kelompok bersertifikat dan kelompok belum bersertifikat.

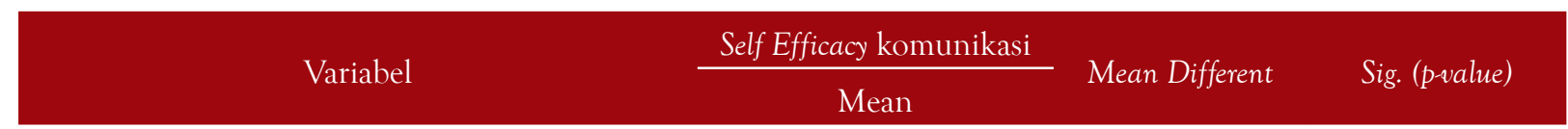

Kelompok Bersertifikat

$\Delta$ Pre test

Bedside Post Test

Teaching Kelompok Belum bersertifikat

$\triangle$ Pre Test

Post Test
Tabel 5 menunjukkan preseptor memiliki hubungan terhadap bedside teaching dengan nilai mean pada kelompok bersertifikat lebih tinggi dari pada kelompok belum bersertifikat, varibel preseptor secara keseluruhan pada tahap bedside teaching mempunyai nilai p-value $<0,05$ yang berarti terdapat hubungan yang bermakna antara preseptor dengan bedside teaching.

Tabel 5. Deskripsi tentang kompetensi preseptor dalam bimbingan bedside teaching

\begin{tabular}{lccc}
\cline { 3 - 3 } \multicolumn{1}{c}{ Variabel } & \multicolumn{2}{c}{ Bedside Teaching } & $\begin{array}{c}\text { Sig. } \\
\text { (p-value) }\end{array}$ \\
\cline { 2 - 3 } Preseptor & 3,9 & $\begin{array}{c}\text { Belum } \\
\text { bersertifikat }\end{array}$ & \\
Perencanaan & 3,4 & 2,5 & 0,000 \\
Briefing & 3,4 & 2.0 & 0,000 \\
Perkenalan & 3,7 & 2,4 & 0,001 \\
Pelaksanaan & 3,8 & 2,9 & 0,000 \\
Debriefing & 3,8 & 1,8 & 0,004 \\
Feedback & & 2,0 & 0,000 \\
\hline
\end{tabular}

Penelitian ini bertujuan untuk mengetahui efektivitas metode pembelajaran bedside teaching terhadap self efficacy komunikasi terapeutik mahasiswa dalam praktik klinik. Hasil analisis menggunakan paired t-test menunjukkan nilai pretest self efficacy pada kelompok bersertifikat dan kelompok belum bersertifikat masih bervariasi. Setelah pembelajaran bedside teaching selama 30 menit sebanyak delapan kali, selanjutnya peneliti menganalisis uji beda hasil nilai posttest self efficacy pada kedua kelompok menunjukkan perubahan nilai signifikan pada kelompok bersertifikat dibandingkan kelompok belum bersertifikat, dikarenakan pada kelompok belum bersertifikat masih diajarkan bedside teaching oleh preseptor yang belum bersertifikat. Analisis menggunakan independent $t$-test diperoleh hasil bahwa terdapat perbedaan yang signifikan antara nilai ratarata pretest dan posttest pada kelompok belum bersertifikat 0,3 dengan kelompok bersertifikat 1,15, perbedaan nilai tersebut disebabkan oleh perbedaan perlakuan yang diberikan kepada kedua kelompok.

Hal ini sesuai dengan penelitian bahawa self efficacy dapat diubah, ditingkatkan melalui pengalaman pemodelan dari orang lain dalam mengerjakan suatu tugas yang sama, selain itu persuasi verbal juga dapat meningkatkan keyakinan tentang kemampuan yang dimiliki melalui arahan individu berupa saran, nasehat, dan bimbingan dalam pencapaian tujuan yang diinginkan, sehingga munculnya kecenderungan akan usaha lebih keras untuk mencapai suatu keberhasilan. ${ }^{12}$ 
Pengajaran bedside teaching menyatukan "triad pembelajaran" pasien, pelajar, dan pembimbing klinik/preseptor. ${ }^{13}$ Melalui persuasi verbal dan pemodelan dari preseptor, self efficacy yang dimiliki mahasiswa lebih mudah dipengaruhi dengan dorongan positif untuk memperkuat kepercayaannya, membekali mahasiswa akan pengetahuan dan pengaturan diri..$^{14,15}$ Bedside teaching sebagai pembelajaran klinis pendidikan dapat mempengaruhi kompetensi mahasiswa dalam keterampilan praktis, berkomunikasi dengan pasien, sehingga kompetensi tersebut berguna bagi mahasiswa ketika masuk ke dunia kerja. ${ }^{16}$

Berdasarkan Piramida Miller pembelajaran klinik yang sukses membutuhkan pengajaran, demonstrasi, pengawasan, dan feedback yang konstan. Pembimbing klinik dapat meningkatkan keterampilan mengajar dengan mengikuti pelatihan preseptor mentor dalam pendidikan kesehatan. Program pelatihan preseptor yang pelaksanaan terstruktur dengan baik berdasarkan pada kebutuhan pembimbing klinik seharusnya berdampak pada keberhasilan dalam hal peningkatan persepsi akan kompetensi, kemampuan dan status profesional mereka. Pengembangan pendidikan klinis melalui pelatihan preseptor mentor dapat menghasilkan empat subkategori: (1) Peningkatan kemampuan berupa pengetahuan tentang cara mengajar mahasiswa sehingga memperkuat kompetensi pembimbing klinik; (2) Peningkatan kepercayaan pada kemampuannya dengan menyusun strategi untuk mendukung pencapaian hasil belajar mahasiswa; (3) Peningkatan penekanan pada refleksi untuk berpikir kritis dalam kemampuannya memecahkan masalah dan bertanggungjawab dalam memfasilitasi pengembangan kemampuan mahasiswa; dan (4) Peningkatan status profesional pembimbing klinik dengan memberikan dukungan pada teman sejawat. ${ }^{17}$

Bedside teaching mencakup beberapa tahap mulai dari persiapan mengajar, sesi bedside teaching, feedback setelah mengajar, dan saran pengembangan lebih lanjut untuk mahasiswa. Penelitian ini telah menilai kemampuan preseptor dalam pengajaran bedside teaching dengan hasil satu sampai empat dari instrumen yang telah dibuat dan diuji validitasnya. ${ }^{18}$ Berikut uraian dari hasil penilaian yang telah dilakukan:

\section{Perencanaan}

Hasil analisis penelitian ini terdapat perbedaan nilai rata-rata tahap perencanaan preseptor sebelum dimulai bedside teaching yaitu pada kelompok bersertifikat 3,9 sedangkan pada kelompok belum bersertifikat 2,5. Pada penelitian ini preseptor bersertifikat telah melakukan persiapan dengan baik berupa memeriksa tingkat pengetahuan dan pengalaman mahasiswa serta menjelaskan kriteria pasien yang akan digunakan. Rendahnya nilai persiapan bedside teaching pada presptor belum bersertifikat disebabkan karena persiapannya yang belum efektif. Hal ini sesuai dengan beberapa penelitian ${ }^{18,19}$ yang menjelaskan tahap perencanaan merupakan kelemahan presptor yang sering terjadi, namun perencanaan pengajaran yang efektif merupakan hal penting. Perencanaan dimulai dari mempertimbangkan rasio mahasiswa, pembimbing klinik dan pasien. Pada penelitian ini preseptor dapat meminimalkan jumlah mahasiswa dan menghindari kerumunan besar mahasiswa di sekitar seorang pasien, karena ini adalah bentuk pengajaran langsung jika terlalu banyak mahasiswa akan mengurangi kualitas pelayanan dan pengalaman belajar mahasiswa berpotensi tidak maksimal, harapannya pembelajaran ini dapat menciptakan rasa nyaman bagi pasien dan mahasiswa menjadi pembelajar aktif. ${ }^{20}$

Persiapan yang memadai sangat penting, preseptor harus mengetahui tingkat pengetahuan dan pengalaman mahasiswa, melalui pertanyaanpertanyaan mengenai tindakan yang akan diajarkan dengan membandingkan teori yang relevan. ${ }^{21}$

Mahasiswa akan lebih paham dan menguasai jika pelaksanaan bedside teaching tepat dan diarahkan pada tindakan yang sesuai. Pembelajaran bedside teaching perlu dipersiapkan dengan tepat dalam waktu yang efektif, selain itu pembimbing klinik juga harus memiliki pemahaman praktis dan teoritis tentang topik yang diajarkan, sehingga mampu mengajarkan beberapa topik dengan menekankan aspek praktis dan teoritis, karena seharusnya preseptor tidak hanya dapat 
memahami aspek praktis saja tetapi juga dapat menempatkan informasi yang diperoleh sebagai dasar teori dalam menerapkan praktik klinik. ${ }^{22}$ Pemilihan dan penyampaian topik saat mengajar sangat mempengaruhi minat mahasiswa, mahasiswa dapat terinspirasi pada topik tersebut dengan belajar lebih aktif, sebaliknya pembimbing klinik yang kurang menarik dalam penyampaian topik dapat menurunkan motivasi mahasiswa. ${ }^{23,24}$ Pembimbing klinik selain kompeten secara klinis, juga harus menguasai pemahaman dasar tentang teori pendidikan dan pelatihan dalam mengajar klinik..$^{25}$ Pengajaran harus pada tingkatan pemahaman yang sesuai pada setiap mahasiswa, pemilihan topik pada mahasiswa tingkat pertama pasti berbeda kompetensinya dengan mahasiswa pada tingkat akhir.

Pembimbing klinik juga penting memahami dan menilai kebutuhan belajar klinik mahasiswa. ${ }^{26}$ Perhatian utama mahasiswa adalah untuk mempersiapkan praktik klinis sesuai dengan yang dibutuhkan, karena hal ini memiliki dampak besar pada apa yang diajarkan. Setiap mahasiswa adalah individu yang memiliki kebutuhan berbeda. Kontrak pembelajaran pada awal pengajaran harus sesuai dengan tujuan yang telah disepakati, memaksimalkan pembelajaran tetapi harus fleksibel. Bobot pencapaian pengajaran bedside teaching akan lebih sedikit pada pasien yang tidak terencana/ dadakan, tetapi pembimbing klinik perlu mempunyai keterampilan manajemen waktu yang baik, termasuk mengevaluasi pembelajaran mahasiswa, pemilihan kasus yang tepat agar sesuai dengan tujuan pembelajaran, memilih pasien yang memiliki riwayat baik. ${ }^{27}$

Pemilihan pasien dapat memiliki dampak besar pada pengalaman klinis mahasiswa. Oleh karena itu, pembimbing klinik memilih pasien untuk pengajaran bedside teaching dengan menentukan faktor-faktor yang relevan dengan mengidentifikasi pasien: pendidikan; bio-psiko-sosial, dan struktural. Pembimbing klinik menentukan pasien yang memiliki kasus sesuai dengan tujuan pembelajaran sehingga dapat memenuhi syarat untuk berpartisipasi.
Ketidaksiapan pembimbing klinik sebelum mengajar bedside teaching erat kaitannya dengan preseptor yang belum mengikuti pelatihan formal dalam pendidikan kesehatan seperti preseptor mentor. Selain itu, preseptor tidak mendedikasikan waktunya untuk pengajaran secara utuh tetapi melakukan bedside teaching secara bersamaan dengan waktu memberikan pelayanan pada pasien, preseptor juga memiliki harapan kecil terhadap dampak pada pengetahuan dan keterampilan klinis mahasiswa, sehingga minat dan motivasi pembimbing klinik dalam pembelajaran yang efektif untuk mencapai kompetensi mahasiswa dapat dibangkitkan melalui pelatihan preseptor mentor. ${ }^{20}$

\section{Briefing}

Hasil analisis penelitian ini terdapat perbedaan nilai rata-rata tahap briefing preseptor sebelum dimulai bedside teaching yaitu pada kelompok bersertifikat 3,4 sedangkan pada kelompok belum bersertifikat 2,0. Nilai briefing bedisde teaching pada preseptor bersertifikat lebih tinggi dibandingkan preseptor belum bersertifikat karena preseptor bersertifikat melakukan briefing terlebih dahulu dengan memberitahu mahasiswa tentang tujuan dan sasaran pengajaran bedside teaching dengan jelas dan sesuai dengan target beserta alasan pemelihan tujuan yang disepakati tersebut, misalnya perasat akan diajarkan sehingga pengajaran terfokus dengan mengikuti tujuan yang jelas, preseptor juga menyampaikan peran yang boleh dilakukan dan tidak boleh dilakukan oleh mahasiswa. Hal ini sesuai dengan hasil-hasil penelitian ${ }^{21,28}$ yang menyebutkan bahwa melibatkan mahasiswa dengan memberi peran khusus melakukan tindakan selama pengajaran dapat mendorong mahasiswa berpartisipasi aktif.

Untuk memaksimalkan hasil belajar mahasiswa preseptor telah menerapkan prinsip dalam keterampilan dengan menanyakan kepada mahasiswa apa yang dilakukan dan bagaimana melakukannya, meninjau tindakan yang diambil dan alasannya. Hal ini sesuai dengan guide yang menjelaskan bahwa preseptor meminta peserta 
didik untuk menjelaskan apa yang akan mereka lakukan kemudian preseptor menunjukkan keterampilan tersebut untuk membantu mereka menetapkan tujuan yang realistis. Preseptor membimbing dengan lembut dan bersikap positif tentang kompetensi apa yang bisa dan tidak bisa dilakukan. Preseptor menggabungkan dunia pembelajaran dengan dunia kerja, meningkatkan pengetahuan tentang cara melakukan tindakan dan juga menjelaskan alasan melakukan tindakan tersebut. ${ }^{29}$

\section{Perkenalan}

Hasil analisis penelitian ini terdapat perbedaan nilai rata-rata tahap perkenalan preseptor sebelum dimulai bedside teaching yaitu pada kelompok bersertifikat 3,4 sedangkan pada kelompok belum bersertifikat 2,4. Preseptor bersertifikat telah memperhatikan persyaratan etis sebelum memulai bedside teaching dengan memperkenalkan mahasiswa dan meminta izin kepada pasien. Hal ini sesuai dengan beberapa studi $^{21}$ yang melaporkan bahwa preseptor dapat menciptakan kenyamanan pasien dengan menginformasikan tujuan dari pertemuan dan meminta persetujuan pasien sebelum pengajaran, preseptor mengenalkan mahasiswa dan pembimbing klinik kepada pasien.

Hasil penelitian menunjukkan bahwa bedside teaching adalah metode yang efektif membantu mahasiswa untuk mencapai kompetensi klinis, mengembangkan keterampilan komunikasi, selain itu memudahkan pembimbing klinik untuk menjadi role model bagi mahasiswa, pasien juga mendapat manfaat berupa informasi terkait dengan kasusnya, pemberian informasi harus fokus pada poin-poin penting dengan menggunakan bahasa jelas agar mudah dipahami pasien mengenai topik yang diberikan.

Walaupun waktu untuk berdiskusi terbatas tetapi komponen bedside teaching dapat dilakukan sesuai dengan peran dan fungsinya secara efektif, sementara pembimbing klinik meminta informed consent dari pasien, mahasiswa dapat menyiapkan diri. ${ }^{30}$

\section{Pelaksanaan bedside teaching}

Hasil analisis penelitian ini terdapat perbedaan nilai rata-rata tahap pelaksanaan bedside teaching yaitu pada kelompok bersertifikat 3,7 sedangkan pada kelompok belum bersertifikat 2,9. Nilai pelaksanaan bedside teaching pada preseptor bersertifikat lebih tinggi dibandingkan preseptor belum bersertifikat disebabkan karena pengajaran bedside teaching oleh preseptor bersertifikat telah melalui tahapan-tahapan yang tepat, berupa demonstrasi, mengobservasi dan mengamati keterampilan mahasiswa, mengambil alih tindakan jika mahasiswa melakukan kesalahan atau ada kekurangan tanpa menegur secara langsung di hadapan pasien. Hal ini sesuai hasil penelitian ${ }^{31}$ yang menyarankan untuk memulai bedside teaching dari demostrasi, preseptor mengajarkan peserta didik dan pasien di waktu yang sama, pemodelan peran berbasis pasien dengan memanfaatkan kesempatan untuk menjawab pertanyaan yang diajukan oleh pasien, sementara mahasiswa dapat mengamati dan belajar dari interaksi preseptor dan pasien tersebut berupa keterampilan komunikasi dan rencana perawatan. Pembimbing klinik telah menjadi contoh yang baik dan bersikap profesional sehingga dapat ditiru dan mahasiswa tidak salah arah.

Preseptor meyakinkan peserta didik akan menjadi praktisi yang kompeten dengan membantu mereka melakukan keterampilan baru sesuai langkah-langkah yang mudah untuk dipelajari, preseptor membimbing mahasiswa secara fisik dan psikis melalui dukungan untuk melatih keterampilan secara langsung pada pasien dengan memperhatikannya secara fokus, pengamatan langsung preseptor saat mahasiswa melakukan tindakan memberi kesempatan peserta didik agar lebih percaya diri. ${ }^{19}$

Memberikan kesempatan peserta didik melakukan keterampilan secara langsung di depan pasien tanpa mengontrolnya agar dapat mengembangkan kompetensinya sendiri selama memenuhi kriteria praktik aman, efektif dan etis. ${ }^{29}$ Keterlibatan mahasiswa yang tepat dalam perawatan pasien juga perlu diperhatikan, 
dengan pengawasan yang memadai untuk memastikan keselamatan pasien. ${ }^{32}$

Jika ada informasi yang disampaikan mahasiswa tidak sesuai dengan kebutuhan pasien, preseptor dapat menambahkan nanti setelah pembelajaran. Kontak langsung dengan pasien merupakan peran penting dalam pengembangan pembelajaran klinis, meningkatkan keterampilan komunikasi, sikap profesional dan empati serta menyediakan layanan promosi kesehatan melalui motivasi. Pengamatan preseptor untuk mengevaluasi kekurangan perencanaan sehingga memungkinkan perencanaan di masa depan akan lebih baik. ${ }^{13}$

Pada penelitian ini, pelaksanaan bedside teaching pada kelompok belum bersertifikat memberikan efek self efficacy komunikasi lebih rendah dibandingkan dengan kelompok bersertifikat. Hal ini dapat dipengaruhi dari pertimbangan kecepatan sesi pembelajaran dengan tepat oleh preseptor, dalam urutan yang logis, dan tidak memberikan waktu mahasiswa untuk mengajukan pertanyaan. Pembimbing klinik seharusnya juga menjalin dan menciptakan hubungan belajar yang baik dan efektif dengan mahasiswa saat pembelajaran dengan bersikap terbuka, ramah, sabar, dapat menekan emosi, dewasa, dapat menilai mahasiswa secara sehat dan menghindari prasangka buruk saat mengajar sehingga terciptanya lingkungan yang mendukung mahasiswa untuk berinteraksi dan berpartisipasi aktif. ${ }^{19,33,34}$

Preseptor bersertifikat telah menerapkan metode pengajaran dengan tepat, saat mahasiswa melakukan kesalahan pemeriksaan atau kesalahan dalam menjawab pertanyaan, preseptor tidak mempermalukan mahasiswa dengan mengkritik secara kasar. ${ }^{20}$

\section{Debriefing}

Hasil analisis penelitian ini terdapat perbedaan nilai rata-rata tahap debriefing bedside teaching yaitu pada kelompok bersertifikat 3,8 sedangkan pada kelompok belum bersertifikat 1,8. Hasil penilaian ini dinilai tepat karena preseptor bersertifikat telah menyediakan waktu untuk menanyakan mahasiswa apakah proses bedside teaching sudah sesuai dengan tujuan pembelajaran yang telah direncanakan, memberikan informasi yang bermanfaat, bersifat menarik dan mengarahkan mahasiswa untuk aktif, berfikir kritis, menganalisis, dan mendiskusikan apa yang terjadi selama bedside teaching dengan mengajukan tanya jawab untuk membahas tindakan yang direfleksikan mahasiswa dan memperkuat tindakan yang tepat.

Beberapa penelitian ${ }^{19,33-35}$ melaporkan bahwa preseptor dapat membuat ringkasan pelajaran yang diberikan kepada mahasiswa, membahas konten yang spesifik mencakup manajemen klinis (misalnya, kepatuhan mahasiswa terhadap protokol atau standar), kompetensi interpersonal dan profesionalisme, keterampilan teknis (misalnya, menghitung DJJ), keterampilan komunikasi, kerja tim, dan masalah perilaku mahasiswa saat bedside teaching, kemudian pembimbing klinik juga dapat menstimulasi mahasiswa untuk berfikir dan berkomunikasi melalui pertanyaan-pertanyaan setelah pembelajaran, memberikan solusi perbaikan tanpa mempermalukan mahasiswa, kesalahan mahasiswa harus diperbaiki dengan bijaksana, mahasiswa juga didorong untuk meningkatkan kinerja pribadi mereka.

Langkah-langkah debriefing: (1) Fase reaksi, di mana mahasiswa mengeluarkan pendapat dan preseptor mendapatkan pandangan tentang apa yang menjadi perhatian untuk mahasiswa, sehingga preseptor dan mahasiswa dapat mendiskusikan dan menganalisis kinerja mahasiswa tersebut. (2) Fase ringkasan, di mana mahasiswa memilih pembelajaran yang tepat untuk kinerjanya di masa depan, sehingga preseptor dapat memberi kesempatan mahasiswa untuk menilai kemajuan pembelajaran selama proses pembelajaran berlangsung. (3) Fase Reaksi, dimana mahasiswa dapat menjelaskan wawasan berharga tentang apa yang paling menarik untuk dipelajari secara terbuka dan memungkinkan preseptor untuk fokus pada dirinya sendiri dan tujuan yang berpusat pada mahasiswa. Ekspresi penyesalan atau kegembiraan adalah hal wajar yang mahasiswa 
rasakan, namun preseptor dapat berperan untuk menghilangkan kekhawatiran mahasiswa dengan berbagi informasi bagaimana mahasiswa dapat mengatasi kecemasan tersebut, dan menunjukkan ketulusan pada pemikiran dan analisis mahasiswa, sehingga dapat berdiskusi secara umum untuk mempelajari pembelajaran yang tepat. ${ }^{36}$

Dalam debriefing preseptor dapat melakukan penilaian formatif, berupa: (1) Mencatat kesenjangan kinerja yang menonjol terkait dengan tujuan yang telah ditentukan sebelumnya, penurunan atau peningkatan kinerja mahasiswa. (2) Memberikan feedback pada kesenjangan kinerja mahasiswa dengan mencari penyebab dan rencana tindakan. (3) Mencari dasar dari kesenjangan melalui faktor yang mempengaruhi pada kinerja mahasiswa. (4) Membantu mahasiswa untuk memecahkan kesenjangan kinerja dengan membahas prinsipprinsip keterampilan yang relevan. ${ }^{36}$

\section{Feedback}

Hasil analisis penelitian ini terdapat perbedaan nilai rata-rata tahap Feedback bedside teaching yaitu pada kelompok bersertifikat 3,8 sedangkan pada kelompok belum bersertifikat 2,0. Preseptor bersertifikat telah memberikan feedback berupa penyampaian keterampilan yang dilakukan mahasiswa berupa sudah baik, perlu diperbaiki dan rencana tindak lanjut untuk memperbaiki keterampilan mahasiswa tersebut. Preseptor belum bersertifikat setelah bedside teaching belum melakukan feedback secara baik.

Sebuah penelitian ${ }^{25}$ melaporkan bahwa pembelajaran bedside teaching belum efektif pelaksanaannya jika masih terdapat kebiasaan buruk pembimbing klinik belum memberikan feedback kepada mahasiswa setelah pendidikan klinik selesai. Pembimbing klinik diharapkan dapat memfasilitasi pembelajaran yang efektif dengan memberikan pembelajaran yang tepat dan menyediakan sesi untuk menerima pertanyaan mahasiswa, mengklarifikasi serta menjelaskan tindakan jika mahasiswa merasa ada kebingungan, masalah yang sensitif tidak diklarifikasi di hadapan pasien untuk menghindari rasa malu, dapat menghargai dan memberi motivasi mahasiswa dengan memberi feedback yang positif, selain itu feedback negatif juga diperlukan setelah bedside teaching. ${ }^{37-40}$

Pembimbing klinik perlu melakukan poin-poin penting dalam memberikan feedback yaitu ${ }^{41}$ : berikan feedback sesegera mungkin setelah pembelajaran dan menyediakan waktu yang cukup untuk berdiskusi, biarkan mahasiswa mengomentari kinerja mereka terlebih dahulu, selanjutnya komentar pembimbing klinik, berikan feedback positif sebelum feedback negatif, feedback menyoroti kekuatan dan kelemahan mahasiswa dari pembelajaran guna mempersiapkan mahasiswa untuk memperbaiki keterampilan kliniknya dan memberikan solusi dalam mengambil langkah-langkah untuk meningkatkan pertemuan di masa depan bagi para peserta didik dan pembimbing klinik. Selanjutnya sebuah rencana harus dibuat untuk memperbaiki masalah yang mungkin muncul. Feedback bertujuan memberikan informasi dan menerangkan dengan jelas kepada mahasiswa untuk mendapatkan hasil terbaik dari pembelajaran bedside teaching untuk kedua belah pihak antara mahasiswa dan pembimbing klinik. ${ }^{40}$

Pelaksanaan bedside teaching yang kurang efektif pada penelitian ini juga dapat dipengaruhi oleh beberapa faktor lain seperti kurang minat dan minimnya komunikasi mahasiswa saat bedside teaching serta sulitnya pembimbing klinik membagi waktu untuk bedside teaching karena bersamaan dengan pemberian pelayanan terhadap pasien. Hasil penelitian menilai kurangnya keberhasilan bedside teaching di departemen klinis karena mahasiswa kurang disiplin dalam pembelajaran, kurangnya akuntabilitas, gaya belajar mahasiswa yang cenderung lebih menyukai belajar di perpustakaan dan mengabaikan pembelajaran bedside teaching, mahasiswa juga mengabaikan keterampilan komunikasi saat bedside teaching karena tidak adanya penilaian, selain itu kepuasan bekerja pembimbing klinik yang buruk dan gaji yang rendah juga diidentifikasi sebagai faktor yang mempengaruhi atas kualitas pengajaran bedside teaching. ${ }^{20}$ 
Penelitian ini memiliki kekuatan dan kelemahan. Kekuatannya adalah penelitian bedside teaching dengan self-efficacy komunikasi baru pertama kali dilakukan dengan menggunakan instrumen SE-12, pelaksanaan bedside teaching juga dinilai oleh mahasiswa menggunakan instrumen yang dibuat oleh peneliti, hasil bedside teaching yang diberikan oleh preseptor bersertifikat efektif terhadap perubahan self-efficacy komunikasi mahasiswa, sehingga dapat menjadi landasan bagi rumah sakit untuk mengikutsertakan pembimbing klinik mengikuti pelatihan preseptor, untuk mendukung proses pembelajaran klinik. Kelemahan penelitian ini adalah jumlah responden tergolong sedikit yaitu 20 responden, walaupun peneliti sudah menggunakan semua mahasiswa yang sedang praktik klinik di dua rumah sakit sebagai responden, pelatihan preseptor mentor dilakukan di luar penelitian dan tidak dikendalikan oleh peneliti, sehingga tidak diketahui proses pelatihan dan evaluasi keefektifan pelatihannya. Kesulitan penelitian ini dalam mengatur waktu untuk pelaksanaan bedside teaching antara pasien, mahasiswa dan preseptor, karena preseptor juga harus membagi waktu setelah memeberikan pelayanan kepada pasien, menyesuaikan pasien yang akan digunakan, menyesuaikan jam dinas praktik klinik mahasiswa.

\section{KESIMPULAN}

Penelitian ini menyimpulkan bahwa self-efficacy komunikasi terapeutik mahasiswa kebidanan lebih tinggi pada kelompok yang diajarkan bedside teaching oleh preseptor bersertifikat dibandingkan dengan kelompok yang diajarkan bedside teaching oleh preseptor belum bersertifikat dalam praktik klinik. Keseluruhan tahap bedside teaching pada kelompok bersertifikat memiliki tingkat kompetensi preseptor lebih baik dibandingkan kelompok belum bersertifikat.

\section{SARAN}

Berdasarkan penelitian ini, saran bagi pembimbing klinik adalah diharapkan pembimbing klinik dapat meningkatkan pengetahuan dengan mengikuti perkembangan ilmu untuk mendapat informasi pembelajaran klinik dan menerapkan bedside teaching yang ideal serta keterampilan mengajar positif dengan salah satu cara mengikuti pelatihan preseptor mentor, merekomendasikan instrumen penilaian pelaksanaan bedside teaching sebagai lembar petunjuk untuk pembimbing klinik selama sesi pembelajaran, meningkatkan kualitas pengajaran klinis dengan merencanakan pengajaran melalui peninjauan kurikulum pembelajaran klinik bedside teaching yang ideal dan menerapkan sikap disiplin serta akuntabilitas. Saran untuk mahasiswa, diperlukan kedisipilinan dalam pembelajaran bedside teaching, aktif bertanya, mengasah kemampuan berkomunikasi dengan pasien, mempersiapkan diri terlebih dahulu agar keyakinan terhadap kemampuan berkomunikasinya meningkat. Bagi penelitian sejenis selanjutnya, diperlukan melibatkan jumlah sampel yang lebih banyak dengan menggunakan beberapa rumah sakit, dapat menambahkan faktor lain yang mempengaruhi self-efficacy komunikasi mahasiswa, mengembangan kurikulum standar bedside teaching dengan menggunakan modul sehingga pelaksanaanya lebih terarah.

\section{DEKLARASI KEPENTINGAN}

Para penulis mendeklarasikan bahwa tidak terdapat konflik kepentingan apapun terkait studi pada naskah ini.

\section{KONTRIBUSI PENULIS}

Dwi Rahmawati - menentukan topik penelitian, melakukan penelitian mengumpulkan data, melakukan analisis data, menulis naskah penelitian, dan publikasi naskah

Ova Emilia - mengembangkan proposal penelitian, memberikan umpan balik dan membantu membentuk penelitian, mengawasi jalannya penelitian, analisis, dan manuskrip

Yekti Satriandari - mengembangkan proposal, memberikan umpan balik dan membantu membentuk penelitian, dan manuskrip

Yoyo Suhoyo - memberikan umpan balik dan membantu membentuk penelitian, membantu membuat instrumen penelitian dan manuskrip. 


\section{DAFTAR PUSTAKA}

1. Xie J, Ding S, Wang C, Liu A. An evaluation of nursing students' communication ability during practical clinical training. Nurse Educ Today. 2013;33:823-7.

2. Joint Commission on Accreditation of Healthcare Organizations. W, Joint Commission Resources I. Joint Commission journal on quality and safety. Jt Comm J Qual Patient Saf. 2003;33:10.

3. Bohren MA, Vogel JP, Hunter EC, Lutsiv O, Makh SK, Souza JP, et al. The Mistreatment of Women during Childbirth in Health Facilities Globally: A Mixed-Methods Systematic Review. PLoS Med. 2015;12(6):1-32.

4. Kementerian Kesehatan RI Badan Penelitian dan Pengembangan. Hasil Utama Riset Kesehatan Dasar. Kementrian Kesehatan Republik Indonesia. 2018.

5. world health organization. Monitoring Health For The Sustainable development goals. 2015.

6. Presiden RI. Undang-Undang Republik Indonesia Nomor 20 Tahun 2003 Tentang Sistem Pendidikan Nasional. 2003.

7. Daryanto. Evaluasi Pendidikan. Jakarta Ri. Vol. 53. 2008. 1689-1699 p.

8. Gonzalo JD, Heist BS, Duffy BL, Dyrbye L, Fagan MJ, Ferenchick G, et al. Content and timing of feedback and reflection: A multicenter qualitative study of experienced bedside teachers. BMC Med Educ. 2014;14(1):1-10.

9. Currie SM. Aspects of the preparation of student midwives for autonomous practice. Midwifery. 1999;15(4):283-92.

10. Williams KN, Ramani S, Fraser B, Orlander JD. Improving bedside teaching: Findings from a focus group study of learners. Acad Med. 2008;83:3.

11. Arikunto. Prosedur penelitian: suatu pendekatan praktik. 2010;

12. Alwisol. Psikologi Kepribadian edisi revisi. Malang : UMM Press; 2009. 76 p.
13. Spencer J, Blackmore D, Heard S, McCrorie P, McHaffie D, Scherpbier A, et al. Patient-oriented learning: A review of the role of the patient in the education of medical students. Med Educ. 2000;34(10):851-7.

14. Pajares F. Self-Efficacy During Childhood and Adolescence and Implications for Teachers and Parents. In: Self-Efficacy Beliefs of Adolescents. 2005. p. 339-67.

15. Press W, Roberts P, Godfrey JR. Freire, P. (1998). Teachers as Cultural Workers: Letters to Those Who Dare Teach. Boulder, CO, Westview Press. 1998;23(1):39-46.

16. Spencer J. ABC of learning and teaching in medicine: Learning and teaching in the clinical environment. Br Med J. 2003;326(7389):591-4.

17. Bengtsson M, Carlson E. Knowledge and skills needed to improve as preceptor: Development of a continuous professional development course - a qualitative study part I. BMC Nurs. 2015;14(1):1-7.

18. Jones R, Higgs R, De Angelis C, Prideaux D. Changing face of medical curricula. Lancet. 2001;357(9257):699-703.

19. T1. Tavabie O, Baker P. Foundation doctors and bedside teaching. BMJ. 2011; avabie O, Baker P. Foundation doctors and bedside teaching. BMJ. 2011;342:1885.

20. Asani M. Bedside teaching: An indispensable model of patient-centred teaching in undergraduate medical education. Niger J Basic Clin Sci. 2014;11:2.

21. Ramani S. Twelve tips to improve bedside teaching. Med Teach. 2003;25(2):112-5.

22. Jones R, Higgs R, De Angelis C, Prideaux D. Changing face of medical curricula. Lancet. 2001;357:699-703.

23. Wright SM, Kern DE, Kolodner K, Howard DM, Brancati FL. Attributes of excellent attending-physician role models. N Engl J Med. 1998;339:27.

24. Busari JO, Scherpbier AJJA. Why residents should teach: A literature review. J Postgrad Med. 2004;50(3):205-10. 
25. Mcleod PJ, Harden RM. Clinical teaching strategies for physicians. Med Teach. 1985;7(2):173-89.

26. Brewer G, Williams A, Sher W. Utilising learning contracts to stimulate student ownership of learning. In: December 2007 AaaE Conference Melbourne [Internet]. 2007. p. 1-8. Available from: http://www.aaee.com.au/conferences/ papers/2007/paper_88.pdf

27. Turner EL, Nielsen KR, Jamal SM, von Saint André-von Arnim A, Musa NL. A review of pediatric critical care in resource-limited settings: A look at past, present, and future directions. Front Pediatr. 2016;4(FEB):1-15.

28. Janicik RW, Fletcher KE. Teaching at the bedside: a new model. Med Teach. 2003;25(2):127-30.

29. Vancouver Coastal Health. Preceptor Resource Guide: Supporting Clincial Learning. In 2006. p. 1-45.

30. Asmara FY. Bedside Teaching: Is it Effective Methods in Clinical Nursing Students Learning. J Ners. 2014;9(1):19-25.

31. Byszewski A, Hendelman W, McGuinty C, Moineau G. Wanted: Role models - Medical students' perceptions of professionalism. BMC Med Educ. 2012;12:115.

32. Rothrock JC. Shared cognition: Reflecting, considering, deliberating. AORN J. 2010;92(3):253-5.

33. Buchel TL, Edwards FD. Characteristics of effective clinical teachers. Fam Med. 2005;37(1):31-5.

34. Amaral G, Bushee J, Cordani UG, Kawasita K, Reynolds JH, Almeida FFM, et al. Teaching Today
A Practical Guide. In: Geoff Petty [Internet]. 2009. p. 1-605. Available from: http://dx.doi. org/10.1016/j.jsames.2011.03.003\%0Ahttps:// doi.org/10.1016/j.gr.2017.08.001\%0Ahttp:// $\mathrm{d} x$. d o i . o r g/ $10.1016 / \mathrm{j}$. precamres.2014.12.018\%0Ahttp:// $\mathrm{d} x \cdot \mathrm{d}$ o i.org/10.1016/j. precamres.2011.08.005\%0Ahttp://dx.doi.org /10.1080/00206814.2014.902757\%0Ahttp:// dx.doi.org/ 10

35. Clay AS, Que L, Petrusa ER, Sebastian M, Govert J. Debriefing in the intensive care unit: A feedback tool to facilitate bedside teaching. Crit Care Med. 2007;35(3):738-54.

36. Rudolph JW, Simon R, Raemer DB, Eppich WJ. Debriefing as formative assessment: Closing performance gaps in medical education. Acad Emerg Med. 2008;15(11):1010-6.

37. Maslow AH. A theory of human motivation. Psychol Rev. 1943;50(4):370-96.

38. S Hartley, D Gill, F Carter, K Walters PB. Teaching Medical Students in Primary and Secondary Care: a Resource Book. J T H E R OYAL Soc O F M EDICINE. 2004;97(8):305-7.

39. Derek S. Wheeler, Hector R. Wong and TPS. Science and Practice of Pediatric Critical Care Medicine. In: Science and Practice of Pediatric Critical Care Medicine. 2009. p. 1-193.

40. Divaris K, Barlow PJ, Chendea SA, Cheong WS, Dounis A, Dragan IF, et al. The academic environment: The students' perspective. Eur J Dent Educ. 2008;12(1):120-30.

41. Hewison D, Kuras M. Book reviews: Book reviews. J Anal Psychol. 2005;50(3):395-403. 